\title{
Attorney preparedness as judged by experts: An empirical pilot study
}

BY THOMAS G. GUTHEIL, M.D., PATRICE MARIE MILLER ED.D., AND MICHAEL LAMPORT COMMONS, PH.D.

This pilot study examines the "preparedness" of attorneys as perceived by respondent expert witnesses. Retaining and opposing counsel were rated with regard to their familiarity with the respondent's qualifications, with the respondent's published writings, and with the psychiatric and legal issues of the case in question. Respondents also addressed whether retaining and opposing counsel were sufficiently ready for deposition, direct examination at trial, and cross examination at trial. Respondents found familiarity with legal issues of the case and readiness for deposition as well as cross examination at trial to be the most salient indicia of "preparedness," particularly when these attributes were ascribed to opposing counsel.

KEY WoRDS: Attorney preparedness, expert witnesses, trial practice, witness examination.

AUTHORS' NOTE: For additional information about this article, please contact: Thomas G. Gutheil, M.D., 6 Wellman Street, Brookline, MA 02446. E-Mail: gutheiltg@cs.com. The authors thank members of the Program in Psychiatry and Law, Department of Psychiatry, Beth Israel Deaconess Medical Center, Harvard Medical School and the staff of the Dare Institute for critical comments; members of the American Academy of Psychiatry and Law for their participation in this pilot study; and Ms. Ellen Lewy for assistance with the manuscript.

(c) 2012 by Federal Legal Publications, Inc. 
According to a study of public perceptions of lawyers, commissioned by the American Bar Association (Shapiro \& Associates, 2002), Americans continue to have ambivalent feelings about lawyers. While, on the one hand, consumers were reported to find that attorneys were knowledgeable about the law, and effective in representing them, on the other hand, they also reported believing that attorneys are "greedy, manipulative, and corrupt," and that attorneys "misrepresent their qualifications, over-promise, are not upfront about their fees, charge too much for their services, take too long to resolve matters, and fail to return client phone calls" (p. 4). In statistical terms, only $19 \%$ said that they were very or extremely confident in the legal profession, which can be contrasted with the same sample's confidence in doctors, which was 50\% (Shapiro \& Associates, 2002). Despite this relatively low opinion of attorneys, it seems as if the public may get their information about attorneys not from direct contact with them, but from television and other media (Pfau, Mullen, Deidrich, \& Garrow, 1995; Spitz, 2000).

The present study is a part of a series of largely unprecedented empirical pilot studies (Commons, Miller, \& Gutheil, 2004; Gutheil, 2000b; Gutheil, 2001; Gutheil, Commons, \& Miller, 2001; Gutheil \& Sutherland, 1999; Strasburger, Gutheil, \& Brodsky, 1997), in which the Program in Psychiatry and the Law, Beth Israel Deaconess Department of Psychiatry, Harvard Medical School, has surveyed different aspects of expert practice, particularly in the area of expert-attorney relations. Taken as a group, these studies appear to us to address indirectly various aspects of professionalism of both attorneys and experts.

The current study investigates the attitudes of expert witnesses about attorneys. Expert witnesses have considerably more contact with attorneys than the average member of the public. They may be exposed to the behavior of attorneys in a given case by being hired by attorneys in 
cases to examine and testify about documents, witnesses and a variety of medico-legal issues. Additional data may come from reading attorney documents and letters; observing attorneys at depositions; and reading, directly observing, or hearing about trial testimony. Such exposure should permit formation of opinions about a number of aspects of attorney behavior.

In undertaking the current study, we assume that attorneys strive for preparedness in their work. To study perceptions of preparedness more directly, we performed this empirical pilot study of expert witnesses' perceptions of the preparedness of retaining and opposing attorneys.

\section{The Rasch model}

In this pilot study, we used a Rasch analysis to show the perceived degree of preparedness in an objective, empirical manner. In order to understand our results, a basic knowledge of Rasch scaling is necessary. Rasch analysis was originally developed for large-scale achievement testing (Rasch, 1980). Its use has since exploded in a variety of disciplines and for a wide range of topics including issues in psychiatry and the law (see Dattilio, Commons, Adams, Gutheil, \& Sadoff, 2006, for a more extensive introduction to the topic). A Rasch analysis, through the use of probabilistic equations, converts raw ratings of items into scales of Rasch scores that have equal intervals. Such a scale can then be used as a type of objective ruler against which to measure the data on survey items as well as on respondents (Andrich, 1988). Statistically speaking, this scale will be linear (Wright \& Stone, 1979). As a result, a change of 1 unit represents the same amount of change going from -2 to -1 as going from 0 to +1 (or any other difference of the same size). After analyzing data with a Rasch model, a number of questions can be answered. In particular, where on the scale of perceived preparedness 
does each item fall? Second, what is the range of scaled values for all items and for all participants?

\section{Method}

Participants
After clearance through our human studies committee and approval from the Research Committee of the American Academy of Psychiatry and Law (AAPL), we distributed an Attorney Preparedness questionnaire developed by the authors. Some participants in the study were voluntary attendees at one of the Twilight Zone workshops (Gutheil, 2001) held at the annual meeting of AAPL. This workshop was advertised as both research and as an opportunity to discuss in a workshop setting attorney-expert matters that were not often openly addressed, i.e., that existed in an insufficiently assessed Twilight Zone. Some attendees had also attended previous such workshops, and the basic theory and early results had been presented as the 2000 AAPL Presidential Address (Gutheil, 2000a). Thus, some familiarity with the format might be expected from at least some attendees. The smaller group of participants came from among participants at the Program in Psychiatry and the Law who had not previously seen the questionnaire.

\footnotetext{
TABLE 1
}

47

$28(60 \%)$

$19(40 \%)$

$35(74 \%)$

$33(70 \%)$

$30(64 \%)$

$24(51 \%)$

$11.34(S D=9.317)$

$48.82(S D=79.067)$

30 
The participants' demographic information is provided in Table 1. This seems to be a fairly typical subsample of those that might attend an AAPL meeting. The majority of participants were physicians $(74 \%)$, were forensically board certified $(51 \%)$, were American Psychiatric Association (APA) members $(70 \%)$, and were AAPL members (64\%). This was a forensically experienced cohort fielding an average of 48.82 cases per year.

Instrument Questions for the Attorney Preparedness questionnaire were informed by the experiences of members of the Program in Psychiatry and the Law. On this questionnaire, participants were asked to think about a recent case in which counsel showed a lack of preparation. They were then asked to evaluate both the retaining and the opposing attorney's level of preparedness in terms of 13 possible aspects, using a 1 (not at all prepared) to 6 (extremely well prepared) scale. Respondents were asked about whether their retaining and opposing attorneys were familiar with the respondent's curriculum vitae, published writing, psychiatric issues of the case, and legal issues of the case. Respondents were also asked whether opposing and retaining attorneys were prepared for deposition, direct examination at trial, and cross examination at trial. The questions used are shown in Table 2.

\section{Results}

Which specific items were judged to have shown a lack of preparedness or a great deal of preparedness? One way to examine this question is in terms of the raw ratings assigned. Recall that the ratings ranged from 1 (not at all prepared) to 6 (extremely well prepared); a rating of 3.5 is the midpoint. As can be seen from the mean ratings in Table 2 , only four items occurred near or slightly below the midpoint, with the remaining nine being above. As is seen in the table, neither retaining nor opposing attorneys were seen as being particularly well prepared in terms of having 


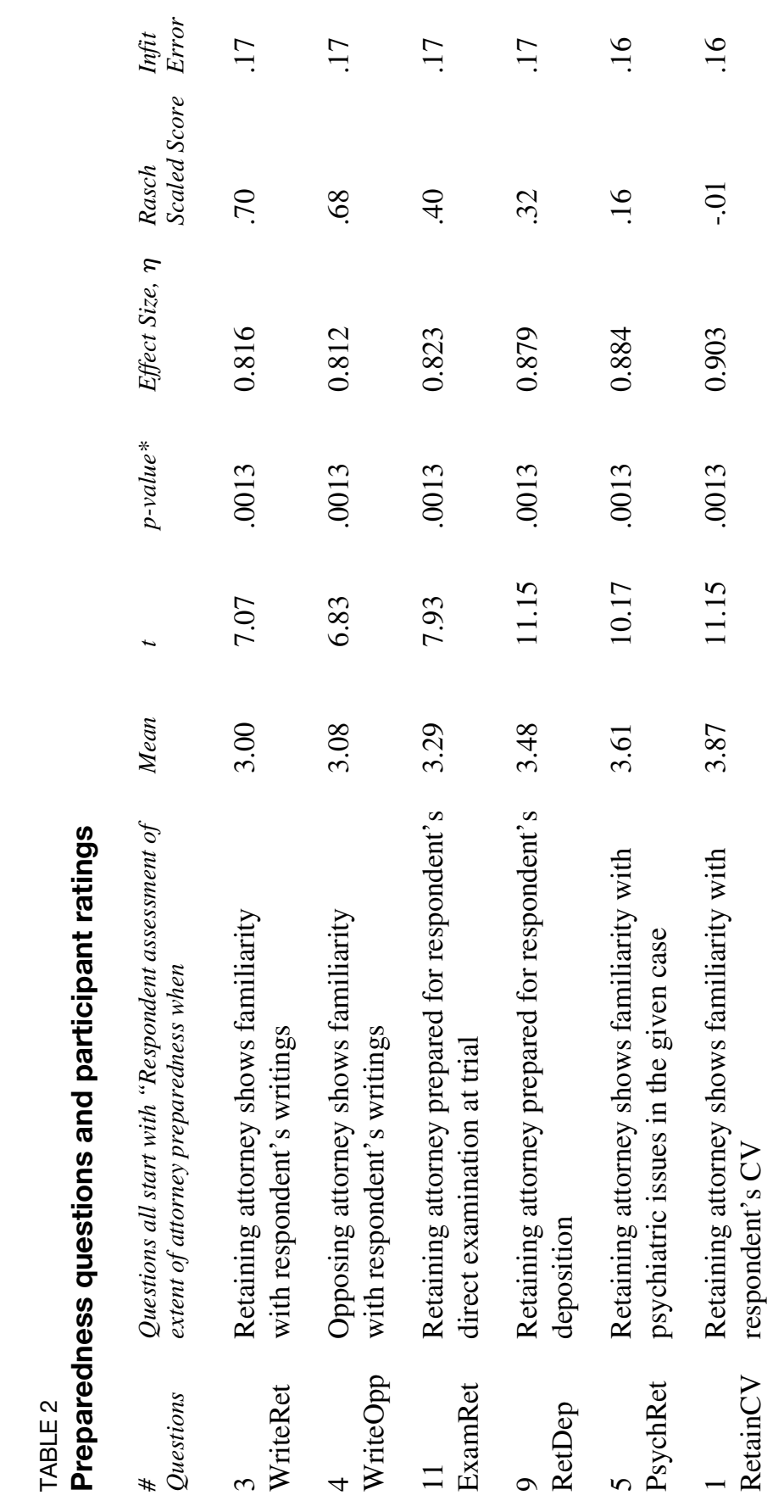




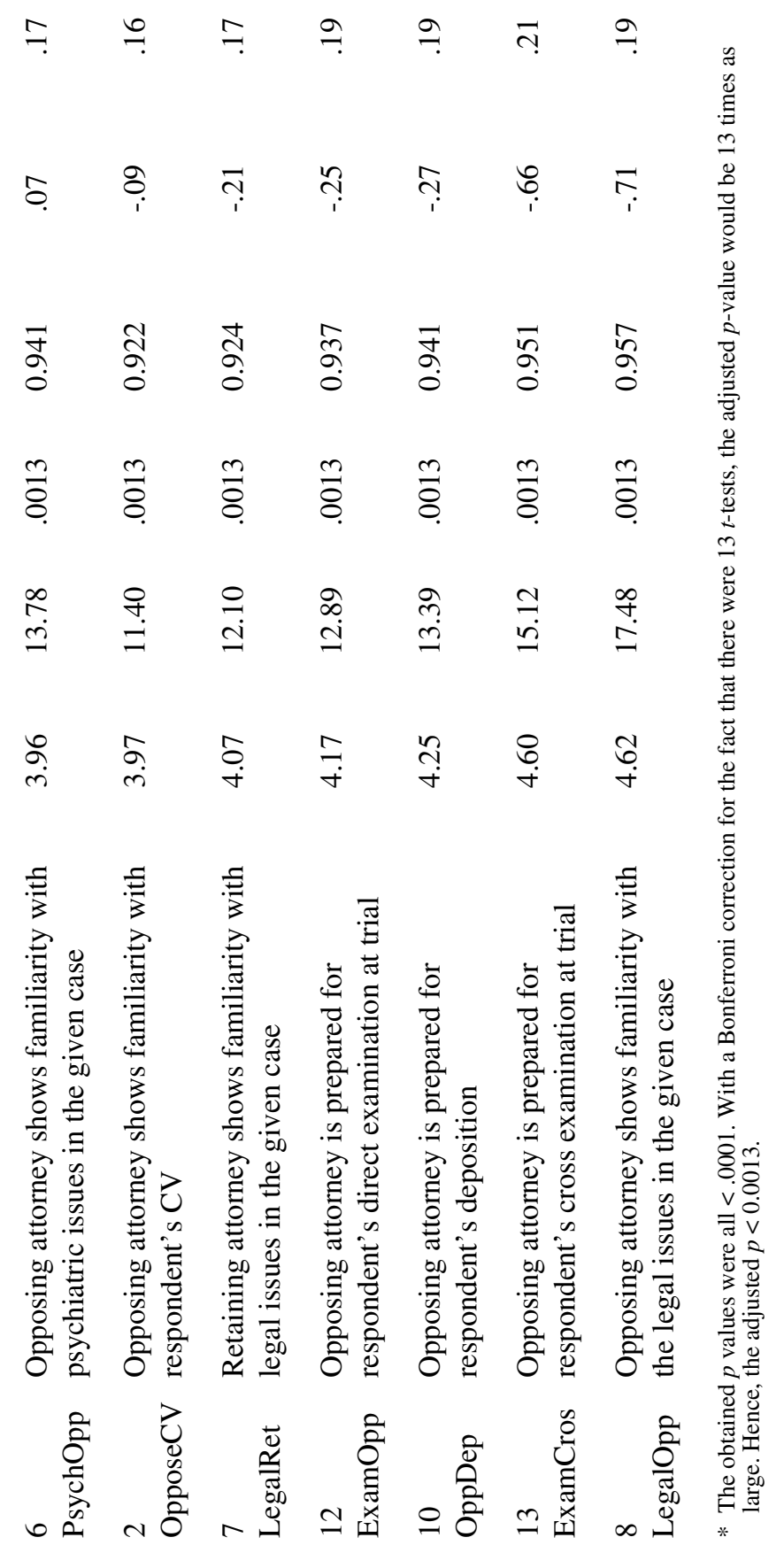


read the expert's own writings. Also slightly below the midpoint was the item "retaining attorney prepared for respondent's direct examination at trial." While this last item is closer to neutral than the other two, it still seems somewhat common for attorneys to be incompletely prepared in this regard. When all of the obtained ratings were tested against a rating of 1 (not at all prepared), all were significantly higher than that value ( $p$ values are shown in Table 2). The effect sizes were large, all $r>0.8$, meaning that a great deal of the variability was accounted for by this difference. When the same obtained ratings were tested against the value of 3.5 , which can be arguably understood as a "middling" level of preparation, only two ratings were found to be significantly above the midpoint: (a) the respondent's assessment of the extent of attorney preparedness when the opposing attorney shows familiarity with the legal issues in a given case $(M=4.62 ; S D=1.12$; $t(28)=5.4, p<.0013, r>0.71)$; and (b) the respondent's assessment of the extent of the opposing attorney's preparedness for the respondent's cross examination at trial $(M=4.60 ; S D=1.19 ; t(24)=4.62, p<.0013, r>0.658)$.

\section{Rasch analysis}

The Rasch analysis offers a slightly different perspective on the perceived preparedness of attorneys. It puts every item onto a linear scale reflecting respondents' assessment of preparedness of attorneys on that item. Whereas the examination of the mean ratings tells us in an ordinal way that on some of the items attorneys were rated as less prepared, the Rasch analysis places all of the items onto an equal-interval, ruler-like scale. With this scale, one can directly compare the scaled value of experts' assessment of the attorney's preparedness in each case.

The Rasch analysis was performed with 47 participants, a small sample. A sample size of 30 assures $95 \%$ confidence, 
but even so, a sample size of 100 is recommended for constructing a test, our sample falling in between (Linacre, 2003). The obtained Rasch scores and the infit errors are shown in Table 2. Because infit errors close to 1 and less than 2 represent a very good fit of the items to the overall scale, for this analysis, the items all fit the scale well, with very small infit errors (Bond \& Fox, 2007; Linacre, 2003). The distribution of the Rasch scores, both for items and participants, and the mean and standard deviation of the scores are seen in Figure 1. Note that the more negative scores, which are at the bottom of the table and figure, reflect a greater perceived preparedness for the item. The range of Rasch scaled scores for the items was small, only $1.4 \operatorname{logits}(S D=0.43)$.

The Rasch procedure calculates a Rasch score or measure for each of the questionnaire items. The item that was perceived as reflecting the most preparedness was "opposing attorney shows familiarity with the legal issues in the given case" (Rasch score -0.71). Second was "opposing attorney is prepared for respondent's cross examination at trial" (Rasch score -0.66). Third was "opposing attorney is prepared for respondent's deposition" (Rasch score -0.27). Fourth was "opposing attorney is prepared for respondent's direct examination at trial" (Rasch score -0.25). The score of the item "retaining attorney shows familiarity with legal issues in the given case" (Rasch score -0.21) was quite similar to that of the preceding item. These findings suggest that experts will most likely perceive attorneys, particularly opposing attorneys, as being relatively well prepared in terms of the legal issues of the case and for deposition, direct examination, and cross examination.

Items that reflected a middling amount of perceived preparedness included whether the retaining and the opposing attorney were familiar with the respondent expert's curriculum vitae. On the other end of the Rasch scale, situations that were perceived as the least important when 


\section{FIGURE 1}

\section{Rausch analysis mapping}

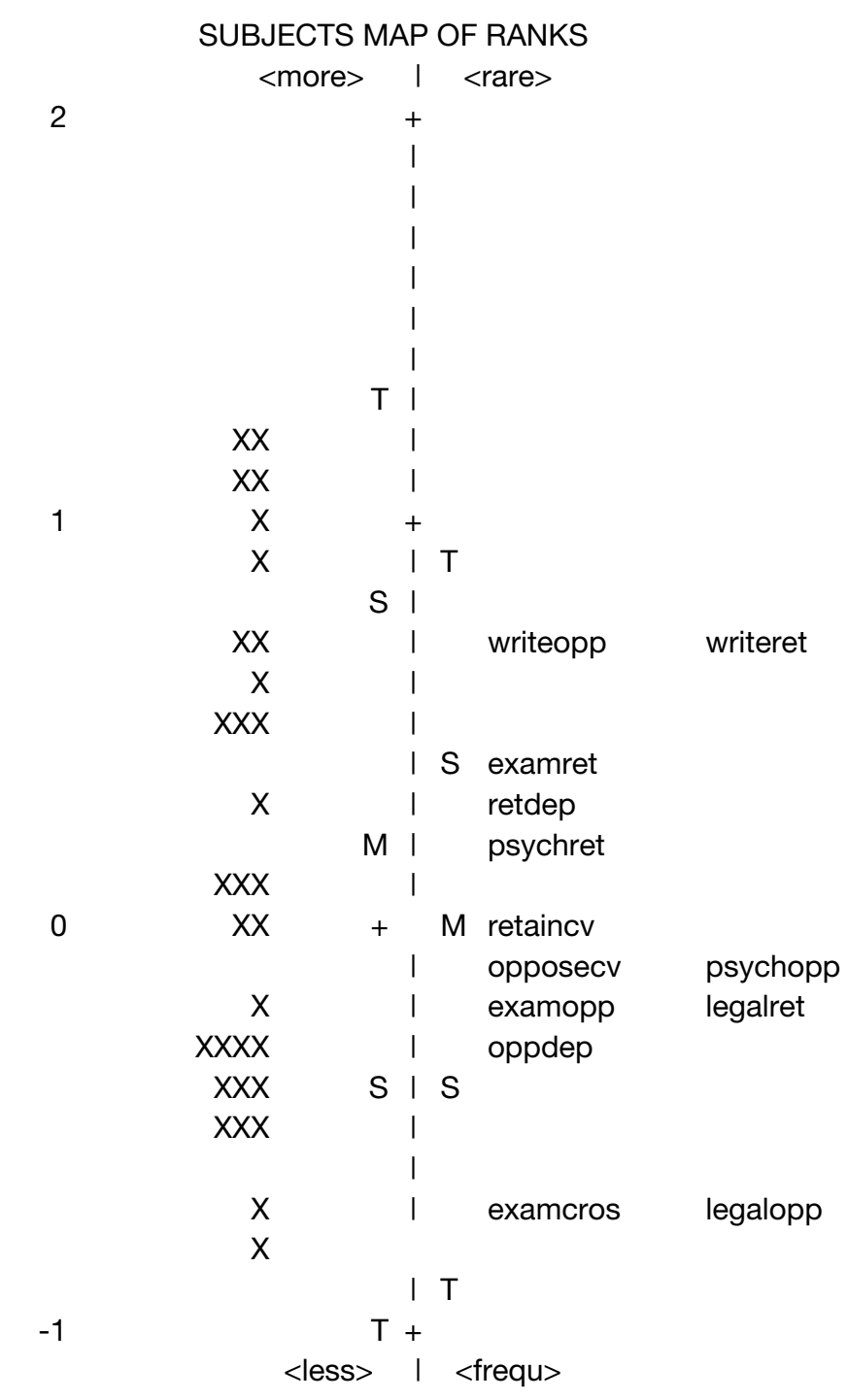

The vertical scale runs from less serious perceived lack of preparedness at the top to lack of preparedness considered most serious at the bottom. On the right are the rated items as found in the table. On the left are the participants' average perceived preparedness for all items, each number representing two participants from the original sample. 
evaluating preparedness was whether the retaining attorney and opposing attorney were familiar with the respondent's published writings. The pair of items with the lowest positive Rasch scores ("retaining attorney shows familiarity with respondent's writings" and "opposing attorney shows familiarity with respondent's writings") had ratings that were significantly smaller than the pair with the highest Rasch scores. "Opposing attorney is prepared for respondent's cross examination at trial" and "opposing attorney shows familiarity with the legal issues in the given case": $M_{1}-M_{2}=$ $-1.37,0.43, t(25)=-16.21, p<.0001, r=.999$.

As seen in Figure 1, the range of scores for the participants (left side of the figure), which was $1.97 \operatorname{logits}(S D=0.59)$, was larger than the range of scores for the items. This suggests that the participants' views had a more normal spread of values when compared to the items themselves. The tight grouping of the items suggests that all the items reflected a relatively similar amount of preparedness.

\section{Discussion}

First, it is important to note that while almost all the experts surveyed had at least one case of lack of preparedness to volunteer, this study in no way assesses how frequently this happened. Instead, experts were asked to report, when they encountered a case of lack of preparedness, on which aspects of the case did they find the attorneys least and most prepared. The results of the mean ratings and of the Rasch analysis essentially agreed. The items that reflected the most perceived preparedness were such items as being familiar with the legal issues in the case and being prepared for cross examination; this was more true in perceptions of the opposing attorney rather than the retaining attorney.

The participants did perceive that the opposing or retaining attorneys were familiar with the respondent's published 
writings. In practice, familiarity with the expert's writings is generally more important to the cross examining (opposing) attorney, since it allows potential impeachment by the expert's own published words. One possible explanation for this low perceived preparedness is the respondents' view that it is more important than reading experts' writings that an attorney be thoroughly familiar with the legal issues of the case and be prepared for deposition, direct and cross examination.

Three suggestions relevant to practice may be derived from our results. First, it may be valuable for the attorney's grasp of relevant issues in an expert's curriculum vitae to add a cover page or summary. The cover page or summary would bring out and highlight those entries most relevant to the particular case at hand. Second, extensive dialog between expert and attorney may be required to insure that relevant legal and psychiatric issues are fully developed before the expert gives testimony in a deposition or trial. Finally, forensic training should incorporate the above issues to aid new experts in most effectively managing these areas of difficulty.

Andrich, D. (1988). Rasch models for measurement. Thousand Oaks, CA: Sage.

Bond, T. G., \& Fox, C. M. (2007). Applying the Rasch model: Fundamental measurement in the human sciences (2nd ed.). Mahwah, NJ: Lawrence Erlbaum.

Commons, M. L., Miller, P. M., \& Gutheil, T. G. (2004). Expert witness perceptions of bias in experts. Journal of the American Academy of Psychiatry and the Law, 32, 70-75.

Dattilio, F. M., Commons, M. L., Adams, K. M., Gutheil, T. G., \& Sadoff, R. L. (2006). Pilot Rasch scaling of lawyers' perceptions of expert bias. Journal of the American Academy of Psychiatry and the Law, 34, 482-491.

Gutheil, T. G. (2000a, October). Presidential address. Speech delivered at the annual meeting of the American Academy of Psychiatry and the Law, Vancouver, BC. 
Gutheil, T. G. (2000b). The presentation of forensic psychiatric evidence in court. Israeli Journal of Psychiatry and Related Sciences, 37, $137-144$

Gutheil, T. G. (2001). Adventures in the twilight zone: Empirical studies of the attorney-expert relationship. Journal of the American Academy of Psychiatry and the Law, 29, 13-17.

Gutheil, T. G., Commons, M. L., \& Miller, P, M. (2001). Personal questions on cross-examination: A pilot study of expert witness attitudes. Journal of the American Academy of Psychiatry and the Law, 29, 85-88.

Gutheil, T. G., \& Sutherland, P. K. (1999). Forensic assessment, witness credibility, and the search for truth through expert testimony in the courtroom. Journal of Psychiatry \& Law, 27, 289-312.

Linacre, J. M. (2003). Winsteps: Multiple-choice, rating scale and partial credit Rasch analysis. Chicago, IL: Mesa Press.

Pfau, M., Mullen, L. J., Deidrich, T., \& Garrow, K. (1995). Television viewing and public perceptions of attorneys. Human Communication Research, 21, 307-330.

Rasch, G. (1980). Probabilistic models for some intelligence and attainment tests. Chicago: University of Chicago Press.

Shapiro, L. J., \& Associates. (2002). Public perceptions of lawyers: Consumer research findings. Chicago: American Bar Association.

Spitz, D. M. (2000). Heroes or villains? Moral struggles vs. ethical dilemmas: An examination of dramatic portrayals of lawyers and the legal profession in popular culture. Nova Law Review, 24, 725750 .

Strasburger, L. H., Gutheil, T. G., \& Brodsky, A. (1997). On wearing two hats: Role conflict in serving as both psychotherapist and expert witness. American Journal of Psychiatry, 154, 448-456.

Wright, B. D., \& Stone, M. H. (1979). Best test design. Chicago: Mesa Press. 
